\title{
LIGHT SCATTERING STUDIES OF FIBRIN CLOTS ${ }^{1}$
}

\author{
BY RICHARD W. GREENE 2 \\ (From the Department of Medicine, State University of New York at Syracuse, College of Medicine, \\ Syracuse, $N$. Y.)
}

(Submitted for publication May 3, 1952; accepted August 9, 1952)

\section{INTRODUCTION}

Hemostasis depends largely on the conversion of fibrinogen to fibrin, catalyzed by the enzyme thrombin. In recent years, there has been considerable advance of knowledge of the formation of thrombin from its various precursors. However, a comparatively small amount of effort has been directed toward studies of the physical nature of the fibrin clot as a possible guide in the better understanding of hemostatic mechanisms in health and disease. In 1947 Ferry and Morrison $(1,2)$ converted purified human fibrinogen to fibrin under various conditions of $\mathrm{pH}$, ionic strength, and fibrinogen concentration, and they measured such properties of the clot as opacity, rigidity, friability, and so forth and proposed two general structures: "The fine and the coarse clot." The fine clot showed small deviation from Rayleigh's law which states that the opacity is inversely proportional to the fourth power of the wavelength, but the coarse clot showed considerable departure from this proportion. They stated: "In a solid structure, such as fibrin clot, it is impossible to calculate explicitly the size and shape of structural units from opacity measurements." The larger strands have been studied by direct microscopic observation $(3,4)$ but the average size strand is too narrow for the limits of optical resolution. The diameter of the fibrin strands has also been measured by the electron microscope (5-8). This instrument, however, has the inherent objection of drying the clot with collapse of the three dimensional network. In the studies to be reported herein, light scatter-

1 These studies were aided by a contract (NONR 12800) between the Office of Naval Research, Department of the Navy and Syracuse University, and by a contract (NONR 12801) between the Office of Naval Research, Department of the Navy and the State University of New York. Both of these contracts were supported jointly by the Office of Naval Research and the Atomic Energy Commission.

2 Fellow of the New York State Division of the American Cancer Society during part of these studies. ing as a method of determining fibrin strand size has been attempted.

\section{THEORY $^{3}$}

Although the fundamental theory of the molecular scattering of light was given by Lord Rayleigh in 1871 , only within the past decade has this method been of practical value in the measurement of the size and shape of particles of biological interest, for P. Debye emphasized that if the particles are comparable in size to the wavelength of light and have a relative index of refraction ${ }^{4}$ near unity, then the system might be treated similarly to a problem in $x$-ray diffraction. There are several reviews of this subject (9-13). Light scattering techniques have been used to determine the size and shape of the fibrinogen molecule and of polymerization of the fibrinogen before gelation (14). However, there are no reports of a theory or techniques for dealing with particles which have the size and shape of fibrin strands. Therefore, a generalized theory of light scattering for cylindrical rods with a relative index of refraction near unity has been developed. The normalized expression for the angular scattering of light by randomly oriented cylindrical rods of length $L$ and radius $R$ is given by:

\section{EQUATION 1}

$$
\begin{array}{r}
\mathrm{I}(\theta)=\frac{1}{\beta^{2}}\left\{\left[\frac{1}{2} \cos 2 \beta+\beta \operatorname{Si}(2 \beta)\right] \frac{\mathrm{J}_{1}{ }^{2}(2 \alpha)}{\alpha^{2}}\right. \\
-\frac{1}{(2 \alpha)^{2}}\left[\frac{\mathrm{J}_{1}(4 \alpha)}{2 \alpha}-2 \mathrm{~J}_{0}(4 \alpha)-1\right] \\
\left.\quad+\frac{1}{2} \sum_{1}^{\infty}(-1)^{\mathrm{n}+1} \frac{(2 \mathrm{n}) !}{(\mathrm{n} !)^{4}} \alpha^{2 n-2} \psi_{\mathrm{n}-1}\right\}
\end{array}
$$

${ }^{8}$ It is appreciated deeply that Professor Peter Debye and Dr. Fred Bueche of Cornell University developed the theoretical concepts presented here and continued to help in the solving of the technical details of the method.

'The relative index of refraction, $m=\frac{n^{\prime}}{n_{0}}$, where $n^{\prime}=$ refractive index of solute particle, $n_{0}=$ refractive index of pure solvent. For protein molecules in solution $\mathrm{m}$ is close to unity. 
where

$$
\psi_{n} \equiv \int_{0}^{1} \frac{1-\left(1-x^{2}\right)^{n}}{x^{2}} \cos (2 \beta x) d x
$$

and

$$
\operatorname{Si}(2 \beta) \equiv \int_{0}^{2 \beta} \frac{\sin u}{u} d u
$$

Also, the $\mathrm{J}_{0}$ and $\mathrm{J}_{1}$ are Bessel functions of zero and first order and

$$
\alpha \equiv \frac{2 \pi \mathrm{R}}{\lambda_{\mathrm{m}}} \sin \frac{\theta}{2}, \quad \beta \equiv \frac{\pi \mathrm{L}}{\lambda_{\mathrm{m}}} \sin \frac{\theta}{2},
$$

where $\lambda_{m}$ is the wavelength of light in the medium.

These expressions may be expanded in series to give:

\section{EQUATION 2}

$$
\begin{aligned}
& \beta^{2} \mathrm{I}(\theta)=\left[\frac{1}{2} \cos 2 \beta+\beta \operatorname{Si}(2 \beta)\right] \frac{\mathrm{J}_{1}^{2}(2 \alpha)}{\alpha^{2}} \\
& -\frac{1}{(2 \alpha)^{2}}\left[3 \frac{\mathrm{J}_{1}(4 \alpha)}{2 \alpha}-2 \mathrm{~J}_{0}(4 \alpha)-1\right]-\frac{\alpha^{2} \sin 2 \beta}{4 \beta} \\
& +\frac{5}{24} \alpha^{4}\left[\frac{\sin 2 \beta}{2 \beta}-2 \frac{\cos 2 \beta}{(2 \beta)^{2}}+2 \frac{\sin 2 \beta}{(2 \beta)^{3}}\right] \\
& -\frac{\alpha^{6}}{144}\left[\frac{\sin 2 \beta}{2 \beta}-2 \frac{\cos 2 \beta}{(2 \beta)^{2}}-6 \frac{\sin 2 \beta}{(2 \beta)^{3}}\right. \\
& \left.\quad-24 \frac{\cos 2 \beta}{(2 \beta)^{4}}+24 \frac{\sin 2 \beta}{(2 \beta)^{5}}\right]+\ldots .
\end{aligned}
$$

Equation 2 is not useful for experimentation. The generalized expression has been reduced to a workable form by assuming the fibrin strands had a radius less than about 1,100 Angstroms and a length ${ }^{5}$ greater than about 30,000 Angstroms, such that $\mathrm{L} / \lambda_{\mathrm{m}}$ is greater than $10, \beta$ is greater than $30, \alpha$ is less than 1.6 and $R / \lambda_{m}$ is less than 0.3. The reduced equation is given by:

\section{EQUATION 3}

$$
\mathrm{I}=\frac{\text { (constant) }(\mathrm{X})\left(\mathrm{J}_{1}^{2}(2 \alpha)\right)}{\alpha^{2}}
$$

where: $I$ is the intensity of light scattered at

The length is not clearly defined since the fibrin strands form a three dimensional network. Most likely, L represents the distance from one junction point of three or more strands to the next. Measurements of this distance from electron microscope photographs would give a false low value since the clot is collapsed and false junction points are created. angle $\theta$, and

$$
\mathrm{X}=\frac{1}{\sin \frac{\theta}{2}}
$$

The constant in front may be adjusted at will for normalization purposes.

\section{MATERIALS AND METHODS}

Preparation of samples. Fibrinogen was obtained from two sources, bovine Fraction I (Armour) and citrated human plasma ( 1 part of 0.109 molar sodium citrate plus 9 parts of venous blood) from hospitalized patients and laboratory personnel. Gamma globulin and albumin were from bovine sources (Armour). The bovine plasma fractions were dissolved under vacuum and dialyzed at $+1 \mathrm{C}$. for 24 hours against phosphate buffers of desired $\mathrm{pH}$ and ionic strength. Citrated fresh human plasma usually has a $\mathrm{pH}$ of 7.5 to 8.0. If lower $\mathrm{pH}$ values were desired, a small amount of $0.1 \mathrm{~N} \mathrm{HCl}$ was added dropwise with constant agitation. If the protein solutions were diluted, 0.15 molar sodium chloride was always used as a diluent. The protein solutions were clarified by centrifuging 30 minutes at $18,000 \mathrm{G}$ (Sorval) at +10 to $+20^{\circ} \mathrm{C}$. Bovine thrombin (Parke, Davis \& Co.) was used to clot both the bovine fibrinogen and human plasma.

Protein analyses. Fibrinogen analysis was performed by the method of Morrison (15), Albumin and globulins were determined by the method of Kibrick (16).

Platelet counts were determined by direct counting using a modified Rees-Ecker diluting fluid (17). $\mathrm{pH}$ was measured on a Cambridge Instrument Co. Model $\mathrm{R}$ glass electrode $\mathrm{pH}$ meter.

Optical density was measured on a model DU Beckman spectrophotometer using $1.0 \mathrm{~cm}$. cells at room temperature, against a 0.15 molar sodium chloride solution blank.

Angular scattering measurements. The intensity of scattered light was measured with a commercial lightscattering microphotometer (American Instrument Co.) in cylindrical, optically good cells with an internal diameter of $34 \mathrm{~mm}$. The light source was a standard mercury vapor tube (AH4) and three filters were routinely used: $\lambda_{v}=436,546,578$ millimicrons $\left(\lambda_{m}=\lambda_{v} / n\right.$, where $n$ is the refractive index). The incident beam was $4 \times 8 \mathrm{~mm}$. and a 10-degree solid angle receiver nose piece was used. All readings were multiplied by $\sin \theta$ to correct for differences in scattering volume. This correction agreed very well with the experimental correction using a dilute fluorescein solution between 60 and 130 degrees. Beyond these limits, the agreement was poor. If no polarizer was used in the incident beam, the observed intensities were also multiplied by $1 / 1+\cos ^{2} \theta$ to correct for polarization. This correction factor proved experimentally to be very good when one sample was measured both with and without a polaroid (horizontal axis) in the incident beam. This indicates that no serious depolarization takes place. If other proteins are present besides fibrinogen, and particularly with plasma where there may be a variable amount of lipemia, the solutions will scatter light before 
they are clotted. To correct for this, a sample of the solution to be clotted was measured for scattering of exactly the same concentration as that which was clotted. These readings of the unclotted solutions were then subtracted from the readings of the clotted solutions. When fibrinogen alone was used the amount of scattering of the fibrinogen solutions was negligible compared to the scattering of the fibrin clot, in the concentrations used. Small changes of the intensity of the incident beam were determined by measuring the intensity of light at 0 degrees with no cell in the system, before and after each set of readings. Readings were taken between 60 and 130 degrees at 5- or 10-degree intervals. Angles lower than 60 degrees were not used since, as $\theta$ becomes small, $\beta$ becomes small, and the assumption of Equation 3 is that $\beta$ is moderately large. Also, at the low angles there is a greater amount of secondary scattering which cannot be accounted for by theory. It is to be noted that absolute scattering intensities are not necessary with this method. Only relative values at the different angles are needed. ${ }^{\circ}$

\section{Method of determining fibrin strand radii from scattering measurements}

Using Equation 3, a set of master curves were constructed, plotting IX vs. $X^{2}$ for various $R / \lambda_{m}$ values, and normalizing them all to one point (we used $\mathrm{X}^{2}=1.21$, $\mathrm{IX}=20.0$, although any convenient point may be used). The corrected experimental intensity readings were then normalized to the same point, graphed, and the $R / \lambda_{m}$ value read by comparing with the master curve. Since $\lambda_{m}$ is known, $\mathrm{R}$ can be computed immediately.

The reason the plot IX vs. $\mathrm{X}^{2}$ was used is as follows: Using Equation 2, a rough approximation to $I(\theta)$ may be obtained if one neglects the higher terms in $\alpha^{2}$ and $1 / \beta^{2}$. One then obtains:

$$
\mathrm{IX}=\frac{\pi}{\mathrm{KL}}\left\{\mathrm{X}^{2}-\mathrm{R}^{2} \mathrm{~K}^{2}+5 / 12 \frac{\mathrm{K}^{4} \mathrm{R}^{4}}{\mathrm{X}^{2}}-\frac{2 \mathrm{X}^{2}}{\pi \mathrm{KL}}\right\},
$$

where $K=2 \pi / \lambda_{m}$.

Unless $\mathrm{R}$ is extremely large, the $\mathrm{R}^{4}$ term may be dropped. Then we obtain:

\section{EQUATION 4}

$$
\mathrm{IX}=\mathrm{AX}^{2}-\mathrm{BX}^{3}-\mathrm{C} \text {, }
$$

where $A=\pi / K L, B=2 / K^{2} L^{2}, C=\pi R^{2} K / L$.

If $L$ is large, Equation 4 may be reduced to

$$
\text { EQUATION } 5
$$

$$
\mathrm{IX}=\mathrm{AX}^{2}-\mathrm{C} \text {. }
$$

' Theoretically it is possible to measure the fibrin strand size by determining the total turbidity as a function of wavelength in a spectrophotometer. This approach was attempted but due to the larger number of approximations necessary in the development of the theory and the technical difficulties in separating the primary beam of light from the low angle scattered light, it was abandoned for the simpler and more accurate angular scattering method.
Using Equation 5 and plotting IX vs. $\mathrm{X}^{2}$ should give a straight line. Approximate values of $R$ can be obtained from this relationship since $R^{2}=\lambda_{m}{ }^{2} C / 40 A$. If $R$ is large, there is concave curvature at low values of $\mathrm{X}^{2}$. If $\mathrm{L}$ is small, there is convex curvature at high values of $\mathrm{X}^{2}$. From Equation 4, it can be seen that $L=A \lambda_{m} / B \pi^{2}$. The use of curvature with the IX vs. $\mathrm{X}^{2}$ plot to determine $\mathrm{L}$ must be with caution since excessive secondary scattering will also give this type of curvature. The curvature is lost (the $\mathrm{X}^{3}$ term of Equation 4 drops out) when $\mathrm{L}$ $\cong 10,000$ Angstroms at the wavelengths which were used. When this happens $L$ may be calculated if the type of network structure is known. If a cubic lattice is postulated, it can be easily seen by geometry that:

$$
\begin{gathered}
\text { EQUATION } 6 \\
L^{2}=3 \pi R^{2} d / c,
\end{gathered}
$$

where $d$ is the density (equal approximately to one) and c the fibrin concentration in gms. per cc. Furthermore, the molecular weight of this segment of the fibrin strand can then be calculated:

$$
\begin{gathered}
\text { EQUATION } 7 \\
\text { M.W. }=\pi R^{2} N_{0} L / \bar{v},
\end{gathered}
$$

where $\mathrm{N}_{0}$ is Avogadro's number, $\overline{\mathrm{v}}$ is the partial specific volume, $=0.725$ (18).

Validity of results. The radii determined on one sample using three different wavelengths usually were within $3 \%$ of each other. Possible errors in the interpretation of the results include:

1. Secondary scattering, if marked, will in general cause a false low result. Since the turbidity increases with decreasing wavelength, the lower wavelengths show more secondary scattering.

2. The assumptions used to derive Equation 3 must be met. Thus, if the radius is greater than $1,100-1,300$ Angstroms, $R / \lambda_{m}$ is no longer less than 0.3 . The $L / \lambda_{m}$ ratio will be discussed later. Between the range of 18 Angstroms (radius of fibrinogen molecule [19]) to 100 Angstroms, the method is not very sensitive due to the nature of the Bessel function.

3. True absorption of light will interfere with the method. Hemoglobin is the chief offender. An absorption curve was determined for the unclotted sample and, if there was an absorption peak in the region of $\mathbf{4 1 0}$ millimicrons, the sample was discarded.

\section{RESULTS AND DISCUSSION}

Any report concerned with fibrin clot measurements must include information about a large number of variables. For the experiments with Fraction I, the following factors were considered important: $\mathrm{pH}$, ionic strength, thrombin concentration, fibrinogen concentration, time that the measurements were taken after adding thrombin, treatment of the fibrinogen in the processing of Fraction I and its resolution, other 


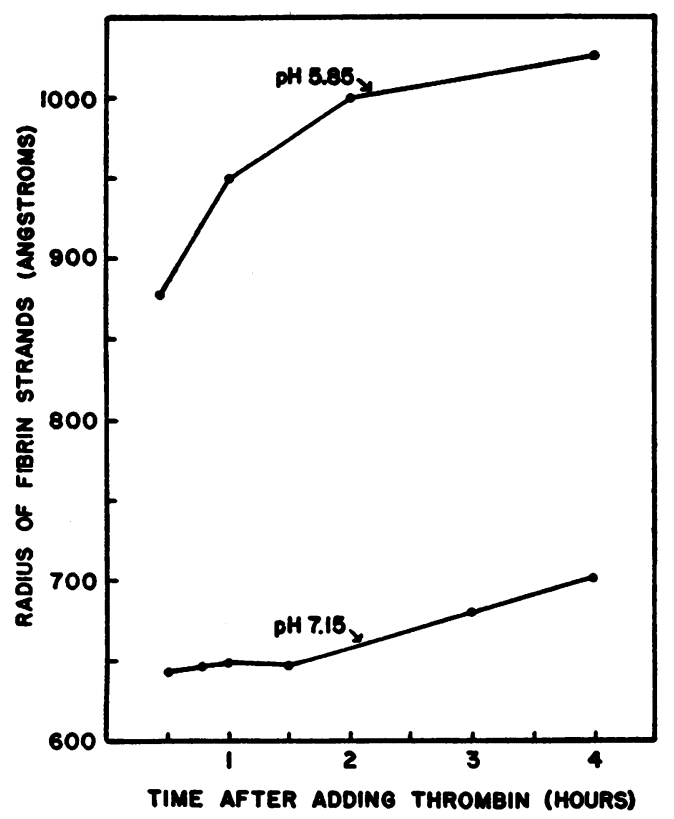

Fig. 1. EFfect of PH ON THE Radius of Fibrin Strands as Calculated from Light Scattering Measurements

proteins present, such as the addition of albumin or gamma globulin plus the other proteins besides fibrinogen present in Fraction I. Without entering into the controversial aspects of blood coagulation, one may consider in plasma, in addition to the above factors, the platelet concentration, certain electrolytes (notably calcium), and perhaps substances said to inhibit or accelerate the action of thrombin. A few variations of the above factors are given below in order to illustrate the method. Extension of these experiments with physiological interpretations is in progress.

\section{Observations on Light Scattering of Fraction I Clots}

\section{A. Effect of $p H$ and time}

In all experiments the ionic strength was kept constant at 0.15 . The temperature during clotting was always 24 to $26^{\circ} \mathrm{C}$. The thrombin concentration was kept constant for both Fraction I and plasma so that the final thrombin concentration was 0.3 units per cc. (15). The proteins other than fibrinogen present in the standard preparation of Fraction I were disregarded. In the first experiment the fibrin strand radii were measured at two different $\mathrm{pH}$ values at various times after adding thrombin (Figure 1). The fibrin concentration was that amount of protein which had clotted at one hour after adding thrombin. In the region of $\mathrm{pH}$ 7.0 to 7.8 this is always at least 90 per cent of the amount clotted at the end of four hours, both by our experiments and those of other workers (20). At more acid $\mathrm{pH}$ values this one hour concentration tends to decrease to about 80 per cent of the four hour value with our fibrinogen and thrombin ranges. In this experiment the onehour fibrin concentration at both $\mathrm{pH}$ values was $0.33 \mathrm{gm}$. per liter. The optical densities (Figure 2) were taken at 436 millimicrons although the curves at other wavelengths showed similar shapes. The optical density curves in general agreed with recent reports $(20,21)$ on the kinetics of the fibrinogen-fibrin reaction.

A more detailed examination of the IX vs. $\mathrm{X}^{2}$ curves at $\mathrm{pH} 5.85$ showed that none had any curvature at 30 minutes. Thus, at this time end-to-end polymerization had proceeded to the point where the fibrin segments were greater than approximately 10,000 Angstroms in length (Equations 4 and 5). However, lateral polymerization continued after 30 minutes of clotting

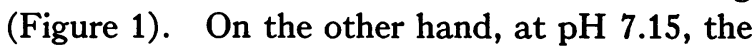
30- and 45-minute samples showed curvature at

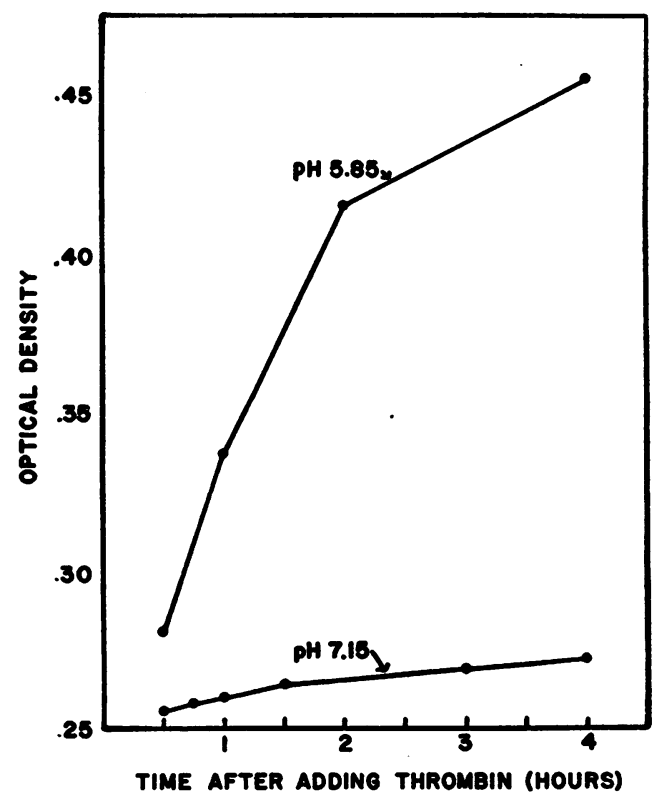

Fig. 2. Effect OF PH ON THE Optical Density of Fibrin Clots 
TABLE I

The effect of fibrinogen concentration on the fibrin strand radii

\begin{tabular}{|c|c|c|c|c|c|c|c|c|c|c|c|}
\hline $\begin{array}{l}\text { Fibrin } \\
\text { conc., } \\
\text { gm./L. }\end{array}$ & $\mathrm{pH}$ & $\mathbf{R}$ in $\AA$ & $\begin{array}{l}\text { Fibrin } \\
\text { conc., } \\
\text { gm./L. }\end{array}$ & $\mathrm{pH}$ & $\mathbf{R}^{\prime}$.in $\AA$ & $\begin{array}{l}\text { Fibrin } \\
\text { conc., } \\
\text { gm./L. }\end{array}$ & $\mathrm{pH}$ & $\mathbf{R}$ in $\AA$ & $\begin{array}{l}\text { Fibrin } \\
\text { conc.. } \\
\text { gm./L. }\end{array}$ & $\mathrm{pH}$ & $R$ in $\AA$ \\
\hline $\begin{array}{l}0.044 \\
0.10 \\
0.12 \\
0.13 \\
0.14 \\
0.16 \\
0.20\end{array}$ & $\begin{array}{l}7.34 \\
7.28 \\
7.12 \\
7.34 \\
7.20 \\
7.17 \\
7.23\end{array}$ & $\begin{array}{l}400 \\
480 \\
600 \\
460 \\
660 \\
550 \\
650\end{array}$ & $\begin{array}{l}0.22 \\
0.28 \\
0.30 \\
0.33 \\
0.33 \\
0.33 \\
0.34\end{array}$ & $\begin{array}{l}7.11 \\
7.21 \\
7.26 \\
7.15 \\
7.15 \\
7.15 \\
7.20\end{array}$ & $\begin{array}{l}470 \\
460 \\
600 \\
650 \\
640 \\
650 \\
550\end{array}$ & $\begin{array}{l}0.37 \\
0.37 \\
0.42 \\
0.44 \\
0.45 \\
0.47 \\
0.47\end{array}$ & $\begin{array}{l}7.21 \\
7.21 \\
7.21 \\
7.22 \\
7.24 \\
7.24 \\
7.24\end{array}$ & $\begin{array}{l}520 \\
540 \\
480 \\
600 \\
520 \\
450 \\
460\end{array}$ & $\begin{array}{l}0.48 \\
0.49 \\
0.49 \\
0.65 \\
0.84\end{array}$ & $\begin{array}{l}7.24 \\
7.24 \\
7.24 \\
7.22 \\
7.21\end{array}$ & $\begin{array}{l}450 \\
480 \\
440 \\
480 \\
470\end{array}$ \\
\hline
\end{tabular}

high values of $\mathrm{X}^{2}$ (theta values of about 60 to 75 degrees); after 45 minutes it was absent. Since the optical density changed very little during the 30-minutes to 4-hour range, it may be assumed that the curvature at the earlier times was not due to secondary scattering but to a

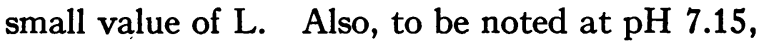
the radius increased only slightly from 30 minutes to 4 hours (Figure 1). This indicated that at this $\mathrm{pH}$ the lateral polymerization preceded the end-to-end polymerization. This agrees with the conclusions of Edsall and Lever (20) and does not conflict with Steiner and Laki (14) who have measured the partially polymerized fibrinogen dimensions just before the gel point, whereas these measurements were considerably after gelation.

The value of $\mathrm{L}$ of the $\mathrm{pH} 7.15$ sample at one hour calculated by using Equation 6 was $1.1 \times 10^{5}$ Angstroms and the molecular weight of this segment was $1.22 \times 10^{11}$. Using the curvature of the IX vs. $\mathrm{X}^{2}$ plot and Equation 4, the $L$ values at 30 and 45 minutes were found to be about 1,600 and 3,400 Angstroms, respectively. If $\mathrm{L}$ is so small, then the conditions used to derive Equation 3 are no longer valid. It should be pointed out that if $R / \lambda_{m} \cong 0.2$ then $L / \lambda_{m}$ may be as small as 3 (instead of greater than 10) and as $\alpha$ gets smaller, the better will be the approximation. These values of $\mathrm{L}(\mathrm{L} \approx 12,000$ Angstroms) are still so low that one may rightly question the value of $R$. The method of obtaining $L$ using Equation 4 was also an approximation. Therefore, both the $\mathrm{R}$ and $L$ values of the 30 - and 45 -minute samples are in doubt, although they probably represent values in the general order of magnitude of the true ones. For purposes of standardization the following data for the determination of radii were recorded one hour after adding the thrombin. This seems justified if the $\mathrm{pH}$ is greater than 7.0.

\section{B. Effect of fibrinogen concentration}

The fibrin strand radii with varying fibrinogen concentrations were determined (Table I). Further analysis of the data was more revealing. As mentioned above, the results obtained on any one sample were usually within 3 per cent of each other as judged by agreement at three different wavelengths. If one sample of fibrinogen was clotted in a number of different cells, the coefficient of variation of the measurements was under 7 per cent. However, from one preparation of fibrinogen to another (Table I) the results varied by as much as 40 per cent. For this reason, in determining the effect of changing one variable, the same preparation of fibrinogen was used. In the $\mathrm{pH}$ range 7.1 to 7.4, there seemed to be very little dependence of the fibrin strand radius on fibrinogen concentration within the concentration range measured. This is understandable for two reasons:

TABLE II

The effect of heating the fibrinogen solution for 30 minutes at $45^{\circ} \mathrm{C}$. before clotting

The $p H$ was 7.21

\begin{tabular}{c|c|c|c}
\hline \multicolumn{2}{c|}{ Unheated } & \multicolumn{2}{c}{ Heated } \\
\hline $\begin{array}{c}\text { Fibrin conc., } \\
\text { gm./L. }\end{array}$ & $\mathrm{R}$ in $\AA$ & $\begin{array}{c}\text { Fibrin conc., } \\
\text { gm./L. }\end{array}$ & $\mathrm{R}$ in $\AA$ \\
\hline 0.84 & 470 & 1.36 & 350 \\
0.42 & 480 & 0.66 & 330 \\
0.28 & 460 & 0.41 & 330 \\
\hline
\end{tabular}

TABLE III

The effect of adding albumin to the fibrinogen solution

\begin{tabular}{|c|c|c|c|c|c|}
\hline $\mathbf{p H}$ & $\begin{array}{c}\text { Fibrinogen, } \\
\text { gm./L. }\end{array}$ & $\begin{array}{c}\text { No albumin } \\
R \text { in } \AA\end{array}$ & $\begin{array}{l}\text { Final albu- } \\
\text { min conc., } \\
\text { gm./L. }\end{array}$ & $R$ in $\AA$ & $\begin{array}{l}\% \text { Increase } \\
\text { of } R\end{array}$ \\
\hline $\begin{array}{l}7.11 \\
7.15\end{array}$ & $\begin{array}{l}0.22 \\
0.33\end{array}$ & $\begin{array}{l}470 \\
660\end{array}$ & $\begin{array}{r}65.0 \\
106.0\end{array}$ & $\begin{array}{l}630 \\
800\end{array}$ & $\begin{array}{l}34 \\
21\end{array}$ \\
\hline
\end{tabular}


TABLE IV

The effect of adding gamma globulin to the fibrinogen solution

The $p H$ was 7.22 and the fibrin concentration 1 was $0.65 \mathrm{gm}$. per liter

\begin{tabular}{c|c}
\hline \hline $\begin{array}{c}\text { Final gamma globulin conc., } \\
\text { gm./L. }\end{array}$ & R in $\AA$ \\
\hline 0.0 & 480 \\
22.2 & 500 \\
48.8 & 490 \\
71.0 & 640 \\
93.3 & 610 \\
\hline
\end{tabular}

TABLE $\mathbf{V}$

The effect of $p H$ on fibrin strand thickness with fresh human plasma

\begin{tabular}{c|c|c|c|c|c}
\hline \hline $\mathrm{pH}$ & $\begin{array}{c}\text { Fibrin, } \\
\text { gm./L. }\end{array}$ & $\begin{array}{c}\text { Albumin, } \\
\text { gm./L. }\end{array}$ & $\begin{array}{c}\text { Globulins, } \\
\text { gm./L. }\end{array}$ & $\begin{array}{c}\text { Platelets } \\
\text { per cu. mm. }\end{array}$ & $\mathrm{R}$ in $\AA$ \\
\cline { 1 - 2 } 7.85 & 0.28 & 6.4 & 2.5 & 1,700 & 730 \\
7.81 & 0.18 & 4.4 & 3.0 & 1,400 & 755 \\
7.34 & 0.24 & 3.2 & 1.8 & 1,000 & 820 \\
6.70 & 0.23 & 5.9 & 1.8 & 1,800 & 790 \\
5.81 & 0.22 & 6.0 & 1.8 & 460 & 880 \\
\hline
\end{tabular}

1) the radius is dependent only on the square root of the concentration (Equation 6), and 2) $L$ is also changing. If the length decreases enough, it is possible that the radius may decrease with increasing concentrations of fibrin, although this has not been noted experimentally.

\section{Effect of heating the fibrinogen solution before clotting}

In the next experiment (Table II) half the fibrinogen preparation was heated in a water bath for 30 minutes at $45^{\circ} \mathrm{C}$. before adding thrombin. Both samples were at $25^{\circ} \mathrm{C}$. when the thrombin was added and the $\mathrm{pH}$ of the samples was 7.21. Heating the fibrinogen solution before clotting decreased the fibrin strand thickness rather markedly.

\section{Effect of adding albumin}

Two experiments were performed in which an albumin solution was added to the fibrinogen solution before adding the thrombin (Table III). In both experiments albumin increased the diameter of the fibrin strands significantly (more than 7 per cent increase).

\section{E. Effect of adding gamma globulin}

A similar experiment was performed using gamma globulin instead of albumin. The $\mathrm{pH}$ was 7.22 , the fibrin concentration $0.65 \mathrm{gms}$. per liter (Table IV). Gamma globulin increased the fibrin strand thickness somewhat. This agrees with a previous observation (22) which showed there was an increase in the amount of light scattered from fibrin clots when egg globulin was added to the clotting mixture.

\section{Observations on Light Scattering of Plasma Clots}

The ionic strength, temperature, thrombin concentration (by clotting with added thrombin) and time of measurements after adding thrombin were kept constant at the same values as above with Fraction I. Platelets were kept at a negligible concentration by centrifugation. The calcium ion concentration contributed less than 2 per cent to the total ionic strength.

\section{A. Effect of $p H$ on fresh citrated plasma}

From five experiments from five different plasma samples (Table V), it appeared that in general the fibrin strands of fresh plasma were somewhat thicker and were less influenced by $\mathrm{pH}$ than Fraction I fibrin.

\section{B. Effect of heating}

Part of one sample of fresh plasma was heated for 30 minutes at $45^{\circ} \mathrm{C}$. before clotting (Table VI). Heating under these conditions did not decrease the fibrin strand thickness to the marked extent noted with Fraction I fibrinogen.

TABLE VI

The effect of heating fresh plasma for 30 minutes at $45^{\circ} \mathrm{C}$. before clotting

\begin{tabular}{|c|c|c|c|c|c|c|}
\hline & $\mathrm{pH}$ & $\begin{array}{l}\text { Fibrin, } \\
\text { gm./L. }\end{array}$ & $\underset{\text { gm./L. }}{\text { Albumin, }}$ & \begin{tabular}{|} 
Globulins, \\
gm./L.
\end{tabular} & $\begin{array}{c}\text { Platelets } \\
\text { percu. mm. }\end{array}$ & $R_{\AA}^{\text {in }}$ \\
\hline $\begin{array}{l}\text { Unheated } \\
\text { Heated }\end{array}$ & $\begin{array}{l}7.34 \\
7.30\end{array}$ & $\begin{array}{l}0.24 \\
0.24\end{array}$ & $\begin{array}{l}3.2 \\
3.2\end{array}$ & $\begin{array}{l}1.8 \\
1.8\end{array}$ & $\begin{array}{r}1,000 \\
860\end{array}$ & $\begin{array}{l}820 \\
700\end{array}$ \\
\hline
\end{tabular}

TABLE VII

Fibrin strand radii of aged blood bank plasma The $\mathrm{pH}$ was 7.12 and platelets were absent

\begin{tabular}{c|c|c|c}
\hline \hline $\begin{array}{c}\text { Fibrin, } \\
\text { gm./L. }\end{array}$ & $\begin{array}{c}\text { Albumin, } \\
\text { gm./L. }\end{array}$ & $\begin{array}{c}\text { Globulins, } \\
\text { gm./L. }\end{array}$ & R in $\AA$ \\
\hline 0.38 & 3.4 & 2.2 & 320 \\
0.72 & 6.4 & 4.2 & 330 \\
\hline
\end{tabular}




\section{Effect of aging}

One experiment was performed using pooled blood bank plasma which had been stored in the frozen state approximately one year before using. The $\mathrm{pH}$ was 7.12 and platelets were absent. The low values (Table VII) were remarkably close to the values obtained with Fraction I which had been heated before clotting (Table II). This suggests that a fibrin strand diameter of 300 to 350 Angstroms is the lowest value possible if gelation occurs.

It should be emphasized that drawing conclusions by comparing experiments on protein fractions with experiments on whole plasma may be misleading. Also, the transition from the fine to coarse type of clot occurs at a different $\mathrm{pH}$ range with human fibrinogen than with bovine fibrinogen (20).

\section{SUMMARY}

1. A generalized expression for the angular scattering of light by randomly oriented cylindrical rods is given. This general expression has been simplified to apply to cylinders of radii between 100 and 1,300 Angstroms, and lengths greater than 12,000 Angstroms.

2. A few illustrations of the application of this theory to the determination of fibrin strand size are presented.

\section{ACKNOWLEDGMENTS}

The author wishes to express sincere appreciation to Dr. Eugene L. Lozner for advice and criticism.

\section{REFERENCES}

1. Ferry, J. D., and Morrison, P. R., Preparation and properties of serum and plasma proteins. VIII. The conversion of human fibrinogen to fibrin under various conditions. J. Am. Chem. Soc., 1947, 69, 388.

2. Ferry, J. D., Protein gels, in Advances in Protein Chemistry. Academic Press, New York, Vol. IV, 1948, pp. 1-79.

3. Tocantins, L. M., Platelets and the structure and physical properties of blood clots. Am. J. Physiol., 1936, 114, 709.

4. Ebbecke, U., and Knüchel, F., Über die Struktur des Fibringerüsts bei der Gerinnung. Arch. ges. Physiol. (Pflügers), 1939, 243, 65.

5. Wolpers, C., and Ruska, H., Strukturenuntersuchungen zur Blutgerinnung. Klin. Wochenschr., 1939, 18, 1077, 1111.

6. Hawn, C. V., and Porter, K. R., The fine structure of clots formed from purified bovine fibrinogen and thrombin: a study with the electron microscope. J. Exper. Med., 1947, 86, 285.

7. Hall, C. E., Electron microscopy of fibrinogen and fibrin. J. Biol. Chem., 1949, 179, 857.

8. Porter, K. R., and Hawn, C. V., Sequences in the formation of clots from purified bovine fibrinogen and thrombin: a study with the electron microscope. J. Exper. Med., 1949, 90, 225.

9. Pirenne, M. H., The Diffraction of X-rays and Electrons by Free Molecules. Cambridge University Press, 1946.

10. Oster, G., The scattering of light and its applications to chemistry. Chem. Rev., 1948, 43, 319.

11. Zimm, B. H., Stein, R. S., Doty, P., Classical theory of light scattering from solutions-A review. Polymer Bull., 1945, 1, 90.

12. Doty, P., and Edsall, J. T., Light scattering in protein solutions, in Advances in Protein Chemistry, Academic Press, New York, Vol. VI, 1951, pp. 35-121.

13. Edsall, J. T., and Dandliker, W. B., Light scattering in solutions of proteins and other large molecules. Its relation to molecular size and shape and molecular interactions. Fortschr. der Chem. Forsch., $1951,2,1$.

14. Steiner, R. F., and Laki, K., Light scattering studies on the clotting of fibrinogen. Arch. Biochem. \& Biophys., 1951, 34, 24.

15. Morrison, P. R., Preparation and properties of serum and plasma proteins. XV. Some factors influencing the quantitative determination of fibrinogen. J. Am. Chem. Soc., 1947, 69, 2723.

16. Kibrick, A. C., On the determination of protein in serum and in fractions obtained from serum with a biuret reagent prepared with sodium hydroxide. J. Lab. \& Clin. Med., 1949, 34, 1171.

17. Pohle, F. S., The blood platelet count in relation to the menstrual cycle in normal women. Am. J. M. Sc., 1939, 197, 40.

18. Armstrong, S. H., Jr., Budka, M. J. E., Morrison, K. C., and Hasson, M., Preparation and properties of serum and plasma proteins. XII. The refractive properties of the proteins of human plasma and certain purified fractions. J. Am. Chem. Soc., 1947, 69, 1747.

19. Edsall, J. T., Foster, J. F., and Scheinberg, H., Studies on double refraction of flow. III. Human fibrinogen and Fraction I of human plasma. J. Am. Chem. Soc., 1947, 69, 2731.

20. Edsall, J. T., and Lever, W. F., Effects of ions and neutral molecules on fibrin clotting. J. Biol. Chem., 1951, 191, 735.

21. Shulman, S., and Ferry, J. D., The conversion of fibrinogen to fibrin. II. Influence of $\mathrm{pH}$ and ionic strength on clotting time and clot opacity. J. Phys. \& Colloid Chem., 1950, 54, 66.

22. Lein, J., A photometric analysis of the reactions of blood coagulation. J. Cell. \& Comp. Physiol., 1947, 30, 43. 